\title{
Anti-Toxoplasma gondii effect of lupane-type triterpenes from the bark of black alder (Alnus glutinosa) and identification of a potential target by reverse docking
} \author{
Jean-Hugues Renault ${ }^{2}$ (D), and Dominique Aubert ${ }^{1}$ (D) \\ ${ }^{1}$ Université de Reims Champagne Ardenne, ESCAPE EA 7510, 51097 Reims, France \\ ${ }^{2}$ Université de Reims Champagne Ardenne, CNRS, ICMR 7312, 51097 Reims, France \\ 3 NatExplore SAS, 51140 Prouilly, France \\ ${ }^{4}$ Université de Reims Champagne Ardenne, MEDyC UMR 7369, 51093 Reims, France \\ ${ }^{5}$ Université de Reims Champagne Ardenne, P3M, 51097 Reims, France
}

Pierre Darme ${ }^{1,2, *}$ (D), Sandie Escotte-Binet ${ }^{1}$, Julien Cordonnier ${ }^{1,2}$, Simon Remy $^{1}$ (D), Jane Hubert ${ }^{3}$, Charlotte Sayagh ${ }^{2}$, Nicolas Borie ${ }^{2}$, Isabelle Villena ${ }^{1}$ (D), Laurence Voutquenne-Nazabadioko ${ }^{2}$, Manuel Dauchez ${ }^{4,5}$ (D), Stéphanie Baud ${ }^{4,5}$ (D),

Received 1 November 2021, Accepted 22 January 2022, Published online 10 February 2022

\begin{abstract}
Toxoplasmosis is a worldwide parasitosis that is generally benign. The infestation may pose a risk to immunocompromized patients and to fetuses when pregnant women have recently seroconverted. Current treatments have numerous side effects and chemoresistance is emerging, hence the need to find new anti-Toxoplasma gondii substances. This study focuses on the antiparasitic potential of lupane-type pentacyclic triterpenes isolated from the bark of black alder (Alnus glutinosa), as well as the hypothesis of their macromolecular target by an original method of reverse docking. Among the isolated triterpenes, betulone was the most active compound with an $\mathrm{IC}_{50}$ of $2.7 \pm 1.2 \mu \mathrm{M}$, a CC$_{50}$ greater than $80 \mu \mathrm{M}$, and a selectivity index of over 29.6. An additional study of the anti- $T$. gondii potential of commercially available compounds (betulonic acid methyl ester and betulonic acid) showed the important role of the $\mathrm{C} 3$ ketone function and the $\mathrm{C} 28$ oxidation level on the lupane-type triterpene in the antiparasitic activity since their $\mathrm{IC}_{50}$ and $\mathrm{CC}_{50}$ were similar to that of betulone. Finally, the most active compounds were subjected to the AMIDE reverse docking workflow. A dataset of 87 T. gondii proteins from the Protein Data Bank was created. It identified calcium-dependent protein kinase CDPK3 as the most likely target of betulin derivatives.
\end{abstract}

Key words: Toxoplasma gondii, Alnus glutinosa, triterpene, Betulone, Inverse docking, Target hypothesis.

Résumé - Potentiel anti-Toxoplasma gondii de triterpènes de type lupane de l'écorce de l'aulne glutineux, Alnus glutinosa, et identification d'une cible potentielle par docking inverse. La toxoplasmose est une parasitose mondiale, généralement bénigne. Les personnes à risque sont les patients immunodéprimés et les fotus chez les femmes enceintes nouvellement séroconverties. Les traitements actuels ont de nombreux effets secondaires et des phénomènes de chimiorésistance apparaissent, d'où la nécessité de trouver de nouvelles substances actives contre T. gondii. Cette étude porte sur le potentiel antiparasitaire des triterpènes pentacycliques de type lupane isolés de l'écorce de l'aulne glutineux (Alnus glutinosa) et formule une hypothèse quant à leur cible protéique par l'utilisation d'une méthode originale de docking inverse. Parmi les triterpènes isolés, la bétulone s'est révélée être la plus active avec une $\mathrm{CI}_{50}$ de $2,7 \mu \mathrm{M} \pm 1,2 \mu \mathrm{M}$, une $\mathrm{CC}_{50}$ supérieure à $80 \mu \mathrm{M}$ et un indice de sélectivité supérieur à 29,6. L'étude complémentaire du potentiel anti-T. gondii de composés disponibles commercialement et analogues à la bétulone (acide bétulonique et methyl ester de l'acide bétulonique) a montré le rôle important de la fonction cétone en $\mathrm{C} 3$ et du degré d'oxydation de la position 28 du squelette triterpénique de type lupane dans l'activité antiparasitaire puisque leurs $\mathrm{CI}_{50}$ et $\mathrm{CC}_{50}$ étaient similaires aux valeurs rencontrées pour la bétulone. Enfin, les composés les plus actifs ont été soumis au flux de travail de docking inverse d'AMIDE. Un ensemble de 87 protéines de $T$. gondii de la Protein Data Bank a été créé. La protéine kinase calcium dépendante CDPK3 a été identifiée comme la cible la plus probable des dérivés de la bétuline.

*Corresponding author: jh. renault@univ-reims. fr

This is an Open Access article distributed under the terms of the Creative Commons Attribution License (https://creativecommons.org/licenses/by/4.0), which permits unrestricted use, distribution, and reproduction in any medium, provided the original work is properly cited. 


\section{Introduction}

Toxoplasma gondii is an apicomplexan parasite responsible for toxoplasmosis. This parasitosis affects approximately one-third of the worldwide population [30]. Although benign in most cases, it can still pose risks to immunocompromized patients or fetuses [24, 30]. First-line therapy consists of the combination of pyrimethamine and sulfadiazine with leucovorin added to prevent hematologic toxicity. Atovaquone or azithromycin may be used as an alternate therapy in combination with pyrimethamine or sulfadiazine for the treatment and prophylaxis of toxoplasmosis when first-line therapy is contraindicated (possibility of serious side effects when pyrimethamine is associated with sulfadiazine). In addition, it was shown that the parasite can develop resistance to treatments [12, 29, 35].

Plants are an important natural reservoir of antimicrobial compounds [1]. In this context, the tree barks are starting material of interest as they protect the heartwood from insect, fungal or microorganism attacks. Black alder (Alnus glutinosa, Betulaceae) is a tree found throughout Europe. A decoction of the bark is used in some traditional medicines to fight against fever, mouth and pharyngeal inflammation, and rheumatism. This species is known for its richness in triterpene compounds such as betulin, betulinic acid, lupeol, and lupenone [15, 34]. Many studies have reported on the biological activity of triterpenes like antitumor, anti-inflammatory, hepatoprotective, gastroprotective, antimicrobial, anti-diabetic, and hemolytic activities [3, 5, 21, 42]. In apicomplexans and more particularly in Plasmodium falciparum, betulinic acid and its analogs disrupt the invasion process of the parasite in vitro [47]. Other betulinic acid derivatives have shown in vivo antiparasitic activity on two Plasmodium species [36]. Ursolic acid derivatives inhibit the in vitro activity of the PfHsp70-1 protein involved in the development of the parasite [37]. For T. gondii, lupane and ursanetype triterpenes from Quercus crispula have demonstrated in vitro antiparasitic activities [14]. Maslinic acid (oleanane triterpene) extracted from Olea europaea could also disrupt the host cell invasion process [10]. Nevertheless, the mechanism of action of triterpenes on $T$. gondii remains largely unknown. Only the docking of ursolic acid derivatives on the TgCDPK1 protein has been performed and has shown a strong affinity between the two entities [46], but the qualification of the interaction of triterpenes on other targets of $T$. gondii has not been investigated.

In a previous study, we demonstrated the strong antiT. gondii activity of $n$-heptane bark extract of black alder (Alnus glutinosa (L.) Gaertn.) amongst 30 extracts of different polarities from 10 temperate tree species [9]. The phytochemical study of this extract revealed the majority presence of lupane type triterpenes. The first bioassays showed a correlation of the biological activity with the presence of triterpenes, especially betulone. An approach combining the determination of the $\mathrm{IC}_{50}$ and $\mathrm{CC}_{50}$ of the compounds of interest and an original inverse molecular docking workflow is proposed to better understand the mechanism of action of these molecules on T. gondii. Molecular docking aims to simulate the interaction between a ligand and a potential target [11]. Docking experimentation finds the best complexes of ligand/receptor according to the energy of binding. The crosslinking of these theoretical data with experimental data can further define the agonist effect of a small molecule toward a receptor. Inverse docking [44] allows for screening of a ligand on multiple receptors. In this way, it is possible to predict the preferred target of a ligand.

In this study, we present the purification of triterpenes of Alnus glutinosa bark extract and their activity on $T$. gondii through the determination of their $\mathrm{IC}_{50}$ values. An inverse docking process was then used to hypothesize the potential target of the most active compounds with the AMIDE reverse docking framework $[8,43]$. The set of proteins was constructed using the Protein Data Bank (PDB) structures available on the Research Collaboratory for Structural Bioinformatics (RCSB) site (mid-2019) after elimination of redundant and low-quality models. Reverse docking was executed using the recently updated AMIDE framework [8, 43].

\section{Material and methods \\ Chemicals and plant materials}

Tree bark of Alnus glutinosa (L.) Gaertn. (Black alder, Betulaceae) was harvested in 2014 in the Champagne-Ardenne territory (northeast France) with authorization from the French "Office National des Forêts" (ONF). A voucher specimen (JH-2014-3) was deposited in the Herbarium of the Botanical laboratory at the faculty of Pharmacy of Reims (University of Reims Champagne-Ardenne, Reims, France). It was dried for $72 \mathrm{~h}$ and milled as described in a previous publication [18].

Betulonic acid (CAS: 4481-62-3) and betulonic acid methyl ester (CAS: 4356-31-4) were purchased from ClickBetulin (Ventspils, Latvia).

Acetonitrile $\left(\mathrm{CH}_{3} \mathrm{CN}\right)$, methanol $(\mathrm{MeOH})$, methyl-tertbutyl ether $(\mathrm{M} t \mathrm{BE})$, and $n$-heptane were purchased from Carlo Erba Réactifs SDS (Val-de-Reuil, France). Deuterated chloroform (chloroform-d) was purchased from Sigma-Aldrich (Saint-Quentin, France).

\section{NMR analysis}

Compounds to analyze were dissolved in $600 \mu \mathrm{L} \mathrm{CDCl}_{3}$. ${ }^{1} \mathrm{H},{ }^{13} \mathrm{C}$, and 2D-NMR (HSQC, HMBC, and COSY) experiments were performed at $298 \mathrm{~K}$ on an Avance AVIII-600 (Bruker, Germany) spectrometer $\left({ }^{1} \mathrm{H}\right.$ at $600 \mathrm{MHz}$ and ${ }^{13} \mathrm{C}$ at $150 \mathrm{MHz}$ ) equipped with a $5 \mathrm{~mm}$ TCI cryoprobe. 2D-NMR experiments were performed using standard Bruker microprograms (TopSpin 3.2 software).

\section{Solid-liquid extraction and centrifugal partition chromatography fractionation}

The dried and powdered A. glutinosa barks (100 g) were macerated in $1.5 \mathrm{~L}$ of $n$-heptane under stirring at room temperature overnight. The extract was then filtered and dried in a rotary evaporator, to give $1.1 \mathrm{~g}$ of extract (yield 1.1\%). Extract fractionation was performed by Centrifugal Partition Chromatography (CPC) on a column with a capacity of $303.5 \mathrm{~mL}$ (FCPE300 ${ }^{\circledR}$, Rousselet-Robatel-Kromaton, Annonay, France) 
containing seven partition disks engraved with 231 twin partition cells $(\approx 1 \mathrm{~mL}$ per twin cell). The CPC column was first filled by pumping the lower phase of the $n$-heptane/methanol $(1: 1, \mathrm{v} / \mathrm{v})$ biphasic solvent system with $1 \%$ water at a flow rate of $50 \mathrm{~mL} / \mathrm{min}$ with a KNAUER Preparative 1800 V7115 pump (Berlin, Germany) in the descending mode and a rotation speed of $500 \mathrm{rpm}(27 \mathrm{~g})$. Then, the $\mathrm{CPC}$ column was equilibrated by pumping the mobile phase (i.e., the upper phase of the same biphasic solvent system) in the ascending mode. The rotation was increased to $1200 \mathrm{rpm}$ (158 g). Bark extract (1.2 g) solubilized in $20 \mathrm{~mL}$ of a mixture of stationary phase and mobile phase $(8: 2, \mathrm{v} / \mathrm{v})$ was injected through a 3725 Rheodyne injector valve after solubilization. Then, 120 fractions were collected every minute using a Pharmacia Superfrac collector (Uppsala, Sweden). The separation was monitored by UV at 210, 254, 280, and $366 \mathrm{~nm}$ (UVD 170S detector, Dionex, Sunnyvale, CA, USA). All fractions were analyzed by thin layer chromatography (TLC) and then pooled according to their chromatographic profile, giving 20 chemically simplified fractions. TLC was performed on Merck 60 F254 pre-coated silica gel plates and developed with $n$-heptane/acetone $(75: 25 \mathrm{v} / \mathrm{v})$. TLC plates were then sprayed with vanillin $(5 \% \mathrm{w} / \mathrm{v}$ in $\mathrm{EtOH})$ and $\mathrm{H}_{2} \mathrm{SO}_{4}$ solution $(50 \% \mathrm{v} / \mathrm{v}$ in $\mathrm{MeOH})$, followed by heating at $100-120^{\circ} \mathrm{C}$ for $2-3 \mathrm{~min}$.

\section{Semi-preparative HPLC purification}

Terpene-rich fractions were solubilized in $\mathrm{M} t \mathrm{BE}$ and then purified using a semi-preparative Uptisphere Strategy C18-HQ $250 \times 10.0 \mathrm{~mm}(5 \mu \mathrm{m})$ column (Interchim, Montluçon, France) and a Dionex HPLC chain equipped with an ASI-100 autosampler, a P580 pump, a UVD 340S diode array detector, an automated fraction collector Ultimate 3000, and Chromeleon 6.8 software. Gradient elution with a constant flow rate of $5 \mathrm{~mL} \cdot \mathrm{min}^{-1}$ was used, starting with $90 \%$ of eluent A $\left(\mathrm{CH}_{3} \mathrm{CN}\right)$ and $10 \%$ of eluent $\mathrm{B}\left(\mathrm{H}_{2} \mathrm{O}\right.$ with $0.025 \%$ trifluoroacetic acid) reaching $100 \%$ of eluent $\mathrm{A}$ in $5 \mathrm{~min}$, followed by isocratic elution with $100 \%$ of eluent A during $25 \mathrm{~min}$. The effluent was monitored at $200 \mathrm{~nm}$. Six triterpenes were purified: $4.7 \mathrm{mg}$ of betulinic acid (3) $(\mathrm{tr}=7.0 \mathrm{~min}), 31 \mathrm{mg}$ of lupenone $(\mathbf{6})(\mathrm{tr}=7.4 \mathrm{~min}), 20.9 \mathrm{mg}$ of betulin $(\mathbf{1})(\mathrm{tr}=$ $8.7 \mathrm{~min}), 2.7 \mathrm{mg}$ of betulone $(4)(\mathrm{tr}=9.2 \mathrm{~min}), 11.7 \mathrm{mg}$ of betulinaldehyde (2) ( $\operatorname{tr}=10.5 \mathrm{~min}$ ), and $16.2 \mathrm{mg}$ of lupeol (5) $(\operatorname{tr}=11.0 \mathrm{~min})$. A phytosterol was also purified, $7.2 \mathrm{mg}$ of $\beta$-sitostenone $(\mathbf{9})(\mathrm{tr}=7.8 \mathrm{~min})$.

\section{Biological assays}

\section{Cell culture}

Vero cells (host cells of $T$. gondii tachyzoite) were purchased at ATCC (reference CCL-81), grown in Iscove Modified Dulbecco Media (IMDM) GlutaMAX medium (Gibco) supplemented with 5\% decomplemented fetal calf serum with $1 \%$ penicillin/streptomycin. The culture was incubated at $37{ }^{\circ} \mathrm{C}$ and $5 \% \mathrm{CO}_{2}$. Toxoplasma gondii tachyzoites (strain $\mathrm{RH}$, type I) were grown in the same conditions as Vero cells except that the concentration of fetal calf serum was $2 \%$.

\section{Stock solutions and dilutions}

Stock solutions at $1 \mathrm{mg} / \mathrm{mL}$ were prepared in cell culture grade dimethyl sulfoxide (DMSO, PanReac AppliChem, Darmstadt, Germany). Subsequent dilutions were made in a culture medium identical to the one used for tachyzoite maintenance.

\section{Cytotoxicity evaluation}

The in vitro cytotoxicity was evaluated on Vero cell cultures using Uptiblue ${ }^{\circledR}$ viable cell-counting assay (Interchim, Montluçon, France). $\mathrm{CC}_{50}$ assays were performed in 96-well plates containing 20,000 Vero cells and $200 \mu \mathrm{L}$ of culture medium identical to the one used for Vero cell maintenance. After $4 \mathrm{~h}$ of incubation, wells were emptied. The $\mathrm{IC}_{50}$ was performed with $100 \mu \mathrm{L}$ of solutions containing the tested compounds with a final concentration range of $0-80 \mu \mathrm{M}$. After $72 \mathrm{~h}$ of incubation, wells were washed with $100 \mu \mathrm{L}$ of phosphatebuffered saline (PBS) (Sigma-Aldrich, Saint-Quentin-Fallavier, France). Then, $100 \mu \mathrm{L}$ of IMDM culture medium supplemented with $2 \%(\mathrm{v} / \mathrm{v})$ of calf fetal serum and $10 \%(\mathrm{v} / \mathrm{v})$ of Uptiblue ${ }^{\circledR}$ were added to each well. Plates were placed at $37{ }^{\circ} \mathrm{C}$ and $5 \%$ of $\mathrm{CO}_{2}$ for $3 \mathrm{~h}$. Spectrophotometric measures were performed at $570 \mathrm{~nm}$ and corrected at $600 \mathrm{~nm}$ on an AMR-100 spectrophotometer (AllSheng, Hangzhou, China).

\section{Screening at $10 \mu \mathrm{M}$ and half-maximal inhibitory concentration $\left(\mathrm{IC}_{50}\right)$}

All the experiments were performed in triplicate. Compound screening was performed at $10 \mu \mathrm{M}$ in 96 -well plates. Thus, 20,000 Vero cells contained in $200 \mu \mathrm{L}$ of culture medium were filled in each well and left to adhere for $4 \mathrm{~h}$ at $37^{\circ} \mathrm{C}$ and $5 \%$ of $\mathrm{CO}_{2}$. Then, 50,000 parasites contained in $50 \mu \mathrm{L}$ of culture medium were filled, followed by $3 \mathrm{~h}$ of incubation in the same conditions. Wells were then emptied and $100 \mu \mathrm{L}$ of solutions containing each drug at a final concentration of $10 \mu \mathrm{M}$ were added. Incubation continued for $72 \mathrm{~h}$. Parasite multiplications were revealed by enzyme immunoassay.

The $\mathrm{IC}_{50}$ assays were processed in the same conditions as previously described [40]. Dilutions were performed in a culture medium. The $\mathrm{IC}_{50}$ was determined using an adapted protocol from Doliwa et al. [12]. Parasites and cells were first fixed with $100 \mu \mathrm{L}$ of cold methanol for $5 \mathrm{~min}$ at $-20{ }^{\circ} \mathrm{C}$. Cells were then rehydrated with $100 \mu \mathrm{L}$ of PBS at room temperature. Wells were then emptied and filled with $60 \mu \mathrm{L}$ of a solution of anti- $T$. gondii rabbit antibody (Ref. 9070-0556, Biorad) diluted at $1 / 1000$. After 1 hour of incubation at $37{ }^{\circ} \mathrm{C}$, wells were washed three times with PBS, and $60 \mu \mathrm{L}$ of anti-rabbit IgG horseradish conjugated goat antibody (Ref. 170-6515, Bio$\mathrm{Rad})$ at $1 / 1000$ were added, followed by $1 \mathrm{~h}$ of incubation at $37^{\circ} \mathrm{C}$. The wells were washed three more times, and $200 \mu \mathrm{L}$ of a solution of o-phenylenediamine dihydrochloride (Sigma, France) was added. After $15 \mathrm{~min}$ at room temperature, the enzymatic reaction was stopped by the addition of $50 \mu \mathrm{L}$ of hydrochloric acid ( $\mathrm{HCl}) 3 \mathrm{M}$. To finish, $200 \mu \mathrm{L}$ of each well were transferred to a new well and a spectrophotometer reading was performed at $492 \mathrm{~nm}$, corrected at $630 \mathrm{~nm}$. Each experiment was performed with three controls: control with host cells 
Table 1. Absorption and permeation computation of the eight lupane-type triterpenes.

\begin{tabular}{|c|c|c|c|c|c|c|c|}
\hline Compound & MW (Da) & $\mathrm{M} \log \mathrm{P}$ & $\begin{array}{c}\text { H-bond } \\
\text { acceptors }\end{array}$ & $\begin{array}{c}\text { H-bond } \\
\text { donors }\end{array}$ & $\begin{array}{c}\text { Lipinski } \\
\text { compliant }\end{array}$ & $\begin{array}{c}\text { GI } \\
\text { absorption }\end{array}$ & $\begin{array}{c}\mathrm{BBB} \\
\text { permeant }\end{array}$ \\
\hline Betulin & 442.72 & 6.00 & 2 & 2 & Yes & Low & No \\
\hline Betulinaldehyde & 440.70 & 5.89 & 2 & 1 & Yes & Low & No \\
\hline Betulinic acid & 456.70 & 5.82 & 3 & 2 & Yes & Low & No \\
\hline Betulone & 440.70 & 5.89 & 2 & 1 & Yes & Low & No \\
\hline Lupeol & 426.72 & 6.92 & 1 & 1 & Yes & Low & No \\
\hline Lupenone & 424.70 & 6.82 & 1 & 0 & Yes & Low & No \\
\hline Betulonic acid & 454.68 & 5.73 & 3 & 1 & Yes & Low & No \\
\hline Betulonic acid methyl ester & 468.71 & 5.92 & 3 & 0 & Yes & Low & No \\
\hline
\end{tabular}

alone, control with host cells and parasites without the drug for parasite multiplication, and control with host cells with parasites and pyrimethamine at $1 \mu \mathrm{M}$.

\section{Selectivity index}

The value of the selectivity index (SI) was calculated for each compound according to the formula:

$$
\mathrm{SI}=\frac{\mathrm{CC}_{50}}{\mathrm{IC}_{50}}
$$

\section{Statistical analysis of in vitro screening}

Statistical analyses were performed using $\mathrm{R}$ software (version 4.1.1) with RStudio IDE (version 1.4.1717). Before pairwise comparison, data normality was assessed by a Shapiro test. Variance homogeneity between samples was then checked using a Fisher test before the pairwise comparisons of screening results with a classical Student $t$-test when both the normality and variance homogeneity null hypothesis were verified, or a Welsh two-sample $t$-test when only the null hypothesis about data normality was verified. Finally, a Wilcoxon rank-sum exact test was used for all other cases. Significance levels for $p$-values are: lower than $0.05\left(^{*}\right)$, lower than $0.01(* *)$, lower than $0.001(* * *)$.

\section{Absorption and permeation computation}

The SwissADME tool (http://www.swissadme.ch/) computes physicochemical descriptors of interest and predicts ADME parameters, pharmacokinetic properties and druglikeness nature of given compounds.

Thus, triterpenes descriptors related to the Lipinski compliance were computed (molecular weight, Moriguchi octanolwater partition coefficient MlogP, H-bond acceptors, H-bond donors) as well as the gastrointestinal (GI) absorption or blood-brain barrier (BBB) permeation (Table 1). Lipinski rules [20] suggest that poor absorption or poor permeation can be associated with a molecular weight higher than $500 \mathrm{Da}$, a $\mathrm{M} \log \mathrm{P}$ higher than 4.15 , to more than $10 \mathrm{H}$-bond acceptors, and to more than $5 \mathrm{H}$-bond donors. Only one violation of these rules is accepted. The BOILED-Egg model [7] estimates the GI absorption and the BBB permeation according to the lipophilicity and the polarity of the compounds.

\section{Inverse docking procedure}

\section{Computer hardware}

All docking procedures were performed on Dell Optiplex 7920 equipped with Intel ${ }^{\circledR}$ Xeon ${ }^{\circledR}$ Silver $42162.1 \mathrm{GHz}$ and NVidia Quadro RTX 4000 running under Ubuntu 20.04.

\section{Ligand and protein preparation for inverse docking}

Inverse docking was performed using the AMIDE v2 framework [8]. Its main characteristic is its speed of obtaining results. Each target (protein) is split into twelve boxes. The ligand is docked on each box and the calculations are distributed to several entities, such as CPU cores or GPUs.

Molecule 2D structures were drawn on ChemDraw 18.0 (https://perkinelmerinformatics.com/). The energy minimized 3D molecular structure of the docked compounds were then obtained with the LigPrep tool from Schrodinger suite (https://www.schrodinger.com/) with OPLS3e force field, ionization at $\mathrm{pH} 7$ without tautomer generation. The resulting files were converted in PDBQT AutoDock readable format with Open Babel (https://openbabel.org/).

The structure of 218 proteins related to $T$. gondii were obtained from the Protein Data Bank (https://rcsb.org/) in mid2019. Protein structures obtained by X-ray crystallography and corresponding to a resolution lower than $3 \AA$ were selected. Thus, a final set of 87 non-redundant structures, including structures with co-crystallized co-factors was created. Then, each protein was submitted to AMIDE to be cut into 12 overlapping docking boxes. The number of AutoDock runs per box was set to 20 .

\section{General docking procedure}

In a first step, betulone, the most in vitro active compound, was docked to the 87 proteins through the reverse docking process. The 10 first betulone/protein clusters obtained after the application of scorings 1 and 2 (described below) were selected and visually analyzed with PyMol 2 (https://pymol.org/2/) to discriminate plausible poses from unlikely poses. In particular, the presence of the ligand in a protein cavity and the existence of hydrogen bonds were verified. Finally, the selected poses of protein-ligand complexes were explored more thoroughly through new docking experiments focusing on a $40 \times 40 \times$ $40 \AA^{3}$ box centered in the area of the best cluster. The parameters of these experiments were as follows: spacing equal to 
$0.375 \AA$, 150 runs using the Solis-Wets local search method combined with the use of AutoDock-GPU. Finally, the generated poses were also investigated with PyMol 2.

\section{Inverse docking analyses and complements}

After the AMIDE process, all protein-ligand complexes were submitted to a modified AutoDock Tools clustering script. The cut-off distance used in the clustering process was chosen based on the average value of the ligand radius of gyration. Each identified cluster was characterized by two parameters: its population and the best free energy of binding among its elements. For a given ligand/protein complex, the statistical character of the docking experiment was considered through the definition of a scoring function (scoring 1, Eq. (1)) that weighs energy and cluster population. Scoring 1 was used to re-rank the clusters of a considered ligand for each protein. Following the same idea, the diverse nature of the protein set was considered through the definition of a second scoring function (scoring 2, Eq. (2)) which weights the differences between the complexes. This second ranking was used to find betulone's most promising target. For the two equations, $\Delta G_{\min }$ was the lowest free energy of binding identified either within a given complex (scoring 1) or among all the complexes (scoring 2), $\Delta G_{x}$ was the free energy of binding of the considered cluster, Pop $_{\max }$ was the highest cluster population identified either within a given complex (scoring 1) or among all the complexes (scoring 2), and Pop $x$ was the population of the considered cluster. For equation (2), Score $1_{\min }$ was the score corresponding to the best complex among all the clusters, and Score $1_{x}$ was the score of the considered cluster. The lower the scoring, the better the result:

$$
\text { Scoring } 1=\sqrt{\left(\frac{\Delta G_{\min }-\Delta G_{x}}{\Delta G_{\min }}\right)^{2}+\left(\frac{\mathrm{Pop}_{\max }-\mathrm{Pop}_{x}}{\mathrm{Pop}_{\max }}\right)^{2}}
$$

\section{See the Equation (2) bottom of the page}

\section{Results}

\section{Purification of the compounds of interest}

The $n$-heptane bark extract of Alnus glutinosa was first fractionated by centrifugal partition chromatography and then, the triterpene-rich fractions were purified by semi-preparative reversed-phase HPLC. Seven compounds were purified and their structures were identified by NMR data analysis as 6 known lupane-type triterpenes: betulin (1) [25, 39], betulinaldehyde (2) [2, 25], betulinic acid (3) [25, 39], betulone (4) [26], lupeol (5) [25, 39], and lupenone (6) [4] together with the $\beta$-sitostenone (9), a phytosterol [32] (Fig. 1). The activity of the purified compounds $(\mathbf{1 - 5}, \mathbf{9})$ was then evaluated against Toxoplasma gondii except for lupenone (6) which was not soluble in DMSO.

\section{Screening at $10 \mu \mathrm{M}$}

Screening of the purified compounds 1-5 and 9 was performed at $10 \mu \mathrm{M}$ (Fig. 2). The phytosterol $\beta$-sitostenone (9) isolated from A. glutinosa did not show any relevant activity. Betulinic acid (3) and betulin (1) showed $49 \%$ and $44 \%$ of parasite growth inhibition, respectively. Lupeol (5) had moderate action of $60 \%$, but this result should be modulated due to the high standard deviation probably due to the low solubility of this triterpene. Betulinaldehyde (2) and betulone (4) showed the highest growth inhibition activity: $93 \%$ and $99 \%$, respectively. Only lupane-type triterpenes 1-5 were thus kept for further studies. For comparison, the parasite growth inhibition of pyrimethamine (compound of reference) is $78 \%$ at $1 \mu \mathrm{M}$ but the compound is cytotoxic at $10 \mu \mathrm{M}$ so it was not used as a positive control at this concentration.

\section{Half maximal inhibitory concentration $\left(\mathrm{IC}_{50}\right)$}

Table 2 shows the $\mathrm{IC}_{50}$ of the lupane-type triterpenes (1-5) as well as of the two commercially structurally related compounds betulonic acid (7) and betulonic acid methyl ester (8). Although the latter has never been described in Alnus glutinosa barks, they were nevertheless introduced into this study for structure-activity relationship considerations. Betulone (4) and betulonic acid methyl ester (8) showed the lower $\mathrm{IC}_{50}$ at $2.7 \mu \mathrm{M} \pm 1.2$ and $3.1 \mu \mathrm{M} \pm 0.4$, respectively. The $\mathrm{IC}_{50}$ of betulinaldehyde (2) and betulonic acid (7) was a little higher, with values of $5.1 \mu \mathrm{M} \pm 0.6$ and $4.3 \mu \mathrm{M} \pm 1.4$, respectively. Betulinic acid (3), betulin (1) and lupeol (5) had similar $\mathrm{IC}_{50}$ at $8.3 \mu \mathrm{M} \pm 2.7,13.3 \mu \mathrm{M} \pm 7.3$, and $13.8 \mu \mathrm{M} \pm 4.0$, respectively. The standard deviation of results obtained for betulin (1) and lupeol (5) was high and could not be reduced because of difficulties to solubilize these compounds in medium culture. Regarding the results of bioassay at $10 \mu \mathrm{M}$, the $\mathrm{IC}_{50}$ of betulinic acid (3) should have theoretically been higher than $10 \mu \mathrm{M}$ but this minor difference is inherent to the graphic determination of $\mathrm{IC}_{50}$.

\section{Cytotoxicity evaluation $\left(\mathrm{CC}_{50}\right)$ and selectivity index}

Table 2 highlights $\mathrm{CC}_{50}$ from $0 \mu \mathrm{M}$ to $80 \mu \mathrm{M}$ calculated for lupane-type triterpenes (1-5). All the $\mathrm{CC}_{50}$ were higher than $80 \mu \mathrm{M}$ and a microscopic verification was performed for each well. Precise values could not be determined since solubility problems were encountered at concentrations higher than $80 \mu \mathrm{M}$. According to the results, betulone had a higher selectivity index (greater than 29.6).

\section{Absorption and permeation computation}

In the light of the strong antiparasitic activity of some of these lupane-type triterpenes, it appears important to investigate

$$
\text { Scoring } 2=\sqrt{\left(\frac{\Delta G_{\min }-\Delta G_{x}}{\Delta G_{\min }}\right)^{2}+\left(\frac{\text { Pop }_{\max }-\text { Pop }_{x}}{\text { Pop }_{\max }}\right)^{2}+\left(\frac{\text { Score } 1_{\min }-\text { Score } 1_{x}}{\text { Score } 1_{\min }}\right)^{2}} .
$$




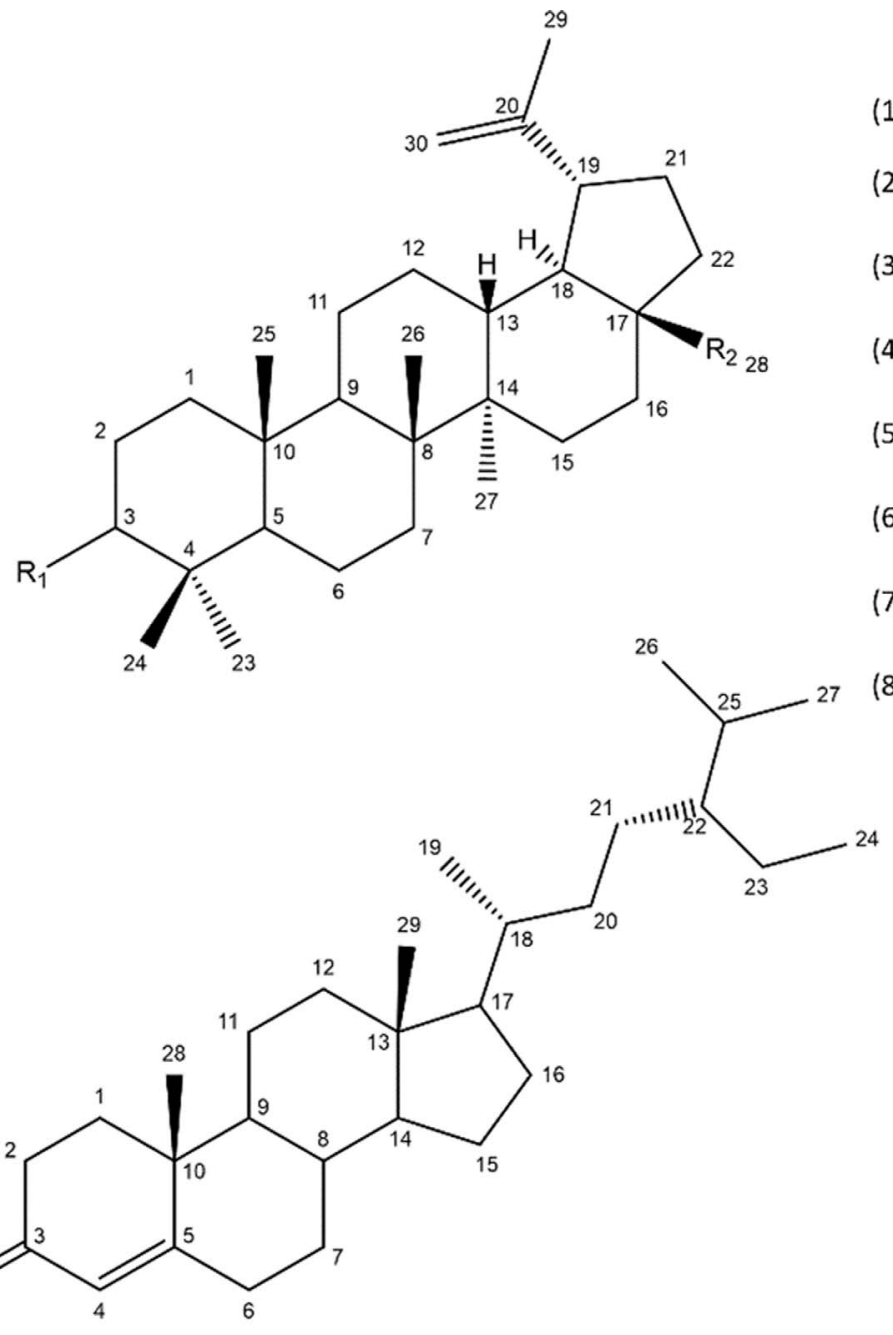

(9) $\beta$-sitostenone
(1)

\begin{tabular}{lll} 
Compound & $\mathbf{R}_{\mathbf{1}}$ & $\mathbf{R}_{\mathbf{2}}$ \\
\hline Betulin & $-\beta-\mathrm{OH}$ & $-\mathrm{CH}_{2} \mathrm{OH}$
\end{tabular}

(2) Betulinaldehyde $-\beta-\mathrm{OH} \quad-\mathrm{CHO}$

(3) Betulinic acid $\quad-3-\mathrm{OH} \quad-\mathrm{COOH}$

(4) Betulone $=\mathrm{O} \quad-\mathrm{CH}_{2} \mathrm{OH}$

(5) Lupeol - $3-\mathrm{OH} \quad-\mathrm{CH}_{3}$

(6) Lupenone $=\mathrm{O} \quad-\mathrm{CH}_{3}$

(7) Betulonic acid $=\mathrm{O} \quad-\mathrm{COOH}$

(8) Betulonic acid methyl $=\mathrm{O} \quad-\mathrm{COOCH}_{3}$ ester

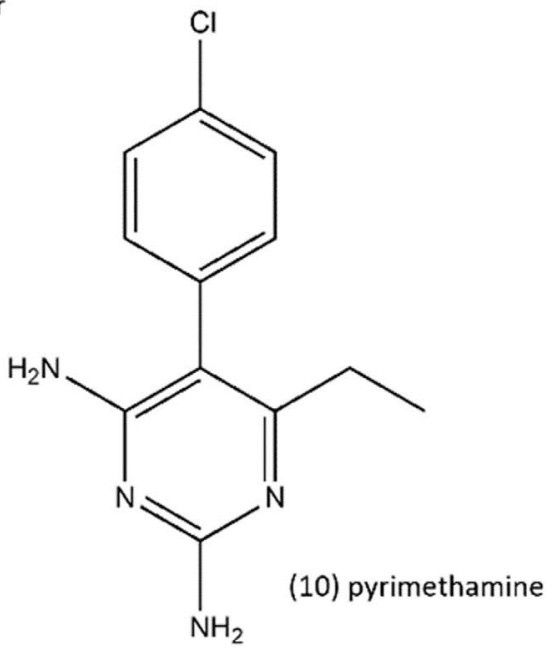

Figure 1. 2D representation of purified compounds $(\mathbf{1 - 6}, \mathbf{9})$ from $n$-heptane extract of A. glutinosa bark, commercially available compounds $(\mathbf{7}, \mathbf{8})$, and reference antiparasitic compound (10).

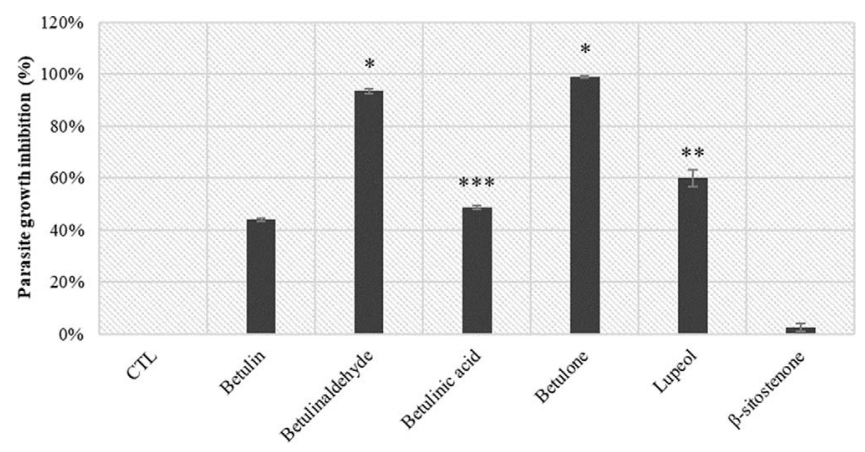

Figure 2. Screening at $10 \mu \mathrm{M}$ of isolated compounds $(\mathbf{1 - 5}, \mathbf{9})$ from $n$-heptane bark extract of A. glutinosa.

the values of critical parameters related to their potential use as in vivo antiparasitics.

As a result, each of the eight compounds turned out to be Lipinski compliant since only their MlogP had a value higher than the limit given by the Lipinski rules. However, their ability to be absorbed by the gastrointestinal tract is low, and the
Table 2. In vitro determination of $\mathrm{IC}_{50}, \mathrm{CC}_{50}$, and $\mathrm{SI}$ from purified and commercial lupane-type triterpenes on $T$. gondii.

\begin{tabular}{lccc}
\hline Compound & $\begin{array}{c}\mathrm{IC}_{50} \\
(\mu \mathrm{M})\end{array}$ & $\begin{array}{c}\mathrm{CC}_{50} \\
(\mu \mathrm{M})\end{array}$ & $\begin{array}{c}\text { Selectivity } \\
\text { index }(\mathrm{SI})\end{array}$ \\
\hline Betulin (1) & $13.3 \pm 7.3$ & $>80$ & $>6.0$ \\
Betulinaldehyde (2) & $5.1 \pm 0.6$ & $>80$ & $>15.7$ \\
Betulinic acid (3) & $8.3 \pm 2.7$ & $>80$ & $>9.6$ \\
Betulone (4) & $2.7 \pm 1.2$ & $>80$ & $>29.6$ \\
Lupeol (5) & $13.8 \pm 4.0$ & $>80$ & $>5.8$ \\
Betulonic acid (7) & $4.3 \pm 1.4$ & $>80$ & $>18.6$ \\
Betulonic acid methyl ester $(\mathbf{8})$ & $3.1 \pm 0.4$ & $>80$ & $>25.8$ \\
Pyrimethamine (10)* & $0.7 \pm 0.2$ & 27.7 & 38.0 \\
\hline
\end{tabular}

* Positive control.

simulation also suggests that they cannot cross the blood-brain barrier.

These data indicate that despite the high in vitro antiparasitic activity of the mentioned lupane-type triterpenes, a pharmacomodulation and/or formulation work on the most active compounds will have to be carried out to improve the 
Table 3. Cluster population, free energy of binding, scoring 1 and 2 of the 10 most relevant complexes containing betulone. The three underlined PDB IDs are selected proteins for re-docking experiments.

\begin{tabular}{lccccc}
\hline Protein & PDB ID & Population & $\Delta \mathrm{G}(\mathrm{kcal} / \mathrm{mol})$ & Scoring 1 (a.u.) & Scoring 2 (a.u.) \\
\hline ENR & 2O50 & 86 & -8.42 & 0.6441 & 0.6577 \\
DHFR & 6AOI & 95 & -7.14 & 0.6247 & 0.6917 \\
DJ-1 & 4XLL & 74 & -8.58 & 0.6802 & 0.7109 \\
PLP1 & 6D7A & 77 & -7.23 & 0.7167 & 0.7334 \\
OA & 5EAV & 68 & -8.52 & 0.7208 & 0.7432 \\
FBP A & 5TKP & 67 & -8.28 & 0.7417 & 0.7532 \\
CDPK3 & 3HZT & 62 & -9.44 & 0.7461 & 0.7658 \\
ROP18 & 4JRN & 61 & -8.82 & 0.7459 & 0.7772 \\
ROP8 & 3BYV & 61 & -8.63 & 0.7318 & 0.7798 \\
MP 2 & 2XGG & 65 & -7.38 & & 0.7887 \\
\hline
\end{tabular}

Table 4. Population, free energy of binding, and ligand efficiency of the three re-docked ligand-complexes. Free energy of binding $(\Delta G)$ is expressed in $\mathrm{kcal} / \mathrm{mol}$. POP stands for cluster population. Ligand efficiency (Lig. Eff.) is an AutoDock Tools computed quantity. The lower the value, the better the complex.

\begin{tabular}{lccccc}
\hline Protein (PDB ID) & & Betulone & Betulonic acid & Betulonic acid methyl ester & Betulinic acid \\
\hline CDPK3 (3HZT) & POP & 149 & 128 & 138 & 110 \\
& $\Delta G$ & -11.52 & -9.61 & -12.74 & -9.79 \\
& Lig. Eff. & -0.36 & -0.30 & -0.39 & -0.30 \\
ENR (2O50) & POP & 137 & -85 & -10.87 & -8.87 \\
& $\Delta G$ & -9.55 & -0.89 & -0.33 & -0.27 \\
ROP8 (3BYV) & Lig. Eff. & -0.30 & 150 & -10.39 & -7.74 \\
& $P O P$ & 150 & -7.34 & -0.31 & -0.23 \\
\hline
\end{tabular}

absorption and permeation parameters while maintaining a satisfactory antiparasitic activity.

\section{Target identification of most active compounds by inverse docking}

An inverse docking strategy using a dataset of $T$. gondii proteins obtained from the Protein Data Bank was performed to identify the potential biological targets of betulone, betulonic acid, betulonic acid methyl ester, and betulinic acid on $T$. gondii, and thus to obtain an initial suggestion of the mechanism of action. Betulone was first screened alone on the 87 proteins to identify the most promising proteins for the docking of the three other compounds. Table 3 presents data related to the 10 most relevant clusters identified from the docking of betulone; ranking is operated according to scoring 2 (Eq. (2)) which considers and compares cluster population, the free energy of binding, as well as scoring 1 (Eq. (1)).

The values of scoring 2 spans between 0.6577 and 0.7887 and thus can be considered close. To narrow down the number of proteins used as targets in the re-docking experiments, a visual study of the 10 complexes was performed with PyMol 2 software. Betulone was selected as a reference since it showed the best in vitro activity. The best complexes were expected to present the ligand in a cavity and show electrostatic binding with the protein [38]. Proteins with PDB ID 2O50, 3HZT and $3 \mathrm{BYV}$ matched the requirements and were therefore selected. The protein with PDB ID 4JRN is equivalent to the PDB ID 3BYV in the defined region; in addition, the poses of the betulone best cluster were similar in the two structures. As a result, the protein with PDB ID 4JRN was not retained in the selection.

Based on previous results, the four most relevant compounds previously identified from in vitro experiments (betulone, betulonic acid, betulonic acid methyl ester, and betulinic acid) were submitted to docking simulations focused on the binding site previously identified for the three proteins. This refined docking was performed with 150 AutoDock runs to better qualify the poses. Results are presented in Table 4. The high population and low free energy of binding of the different complexes suggest strong binding between the four ligands and the three proteins. The additional AutoDock value of ligand efficiency was added to help in the selection of the best complex. All the compounds and proteins showed high affinity. The first hit was the complex betulonic acid methyl ester$3 \mathrm{HZT}$ with a ligand efficiency of -0.39 , followed by the complex betulone-3HZT with a ligand efficiency of -0.36 . The two cited complexes are described below as well as the first hit complex betulone-2O50 identified in Table 3 .

The best ligand efficiencies were obtained for the complexes with the ligands betulone and betulonic acid methyl ester (BAME) with the proteins with PDB IDs 3HZT, 2O50, and 3BYV. They were visualized with PyMol (Fig. 3). Each of the ligands was in a folded area that could be assimilated to a pocket (see inserts of Fig. 3). In addition, betulone and BAME were systematically in the binding site of original ligands for PDB IDs 3HZT and 2050 which ensures that the ligands were docked to an area of interest. This comparison was not possible 


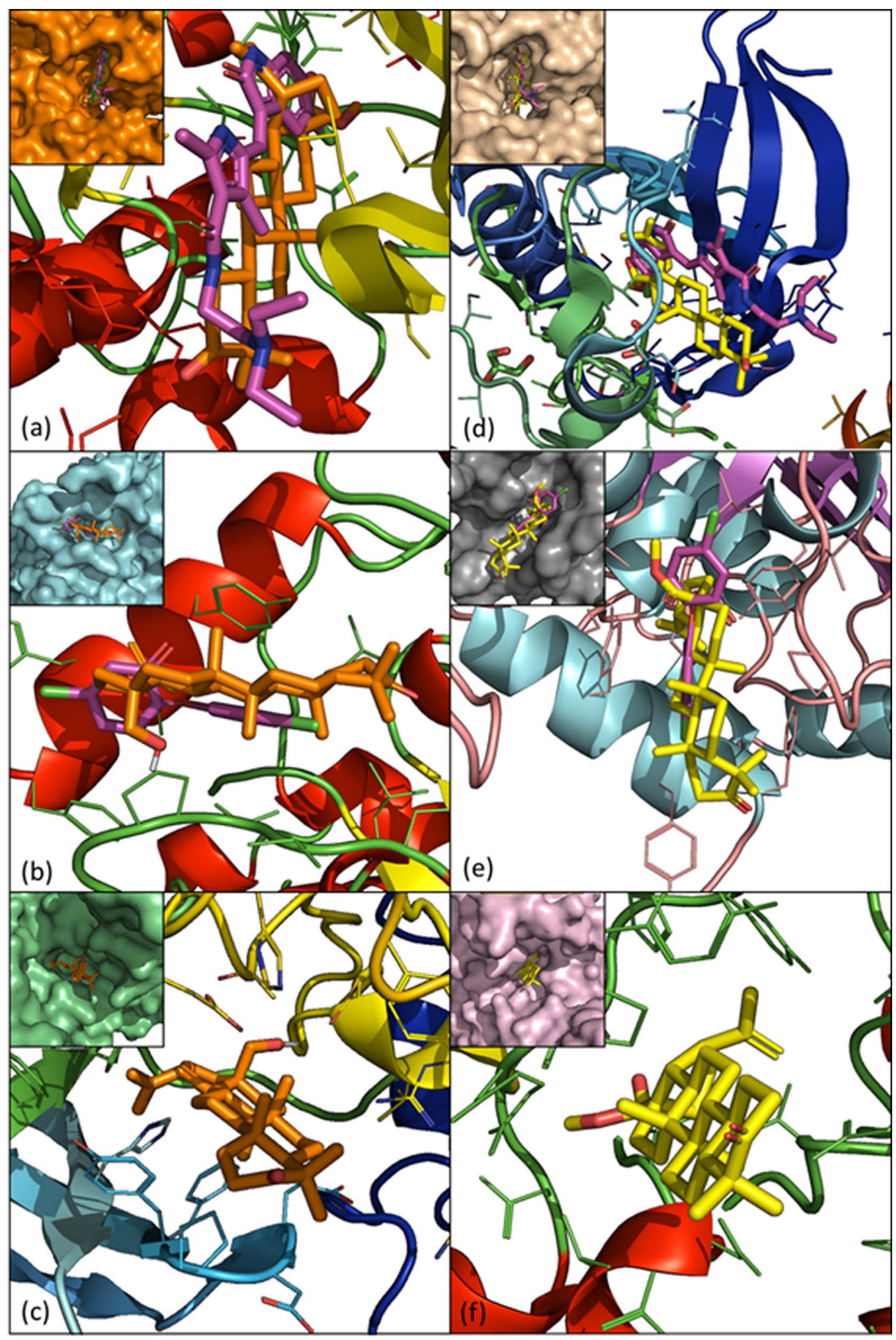

Figure 3. PyMol visualization of PDB ID 3HZT (CDPK3), $2 \mathrm{O} 50$ (ENR), and 3BYV (ROP8). (a) 3HZT with betulone (orange) and cocrystallized ligand (PDB ID J60, pink). (b) 2050 with betulone (orange) and triclosan (pink). (c) 3BYV with betulone (orange). (d) 3HZT with BAME (yellow) and co-crystallized ligand (PDB ID J60, pink). (e) 2050 with BAME (yellow) and triclosan (pink). (f) 3BYV with BAME (yellow). The inserts of each panel are the co-location of ligands and known inhibitors (if available) in the pockets (surfaces). 


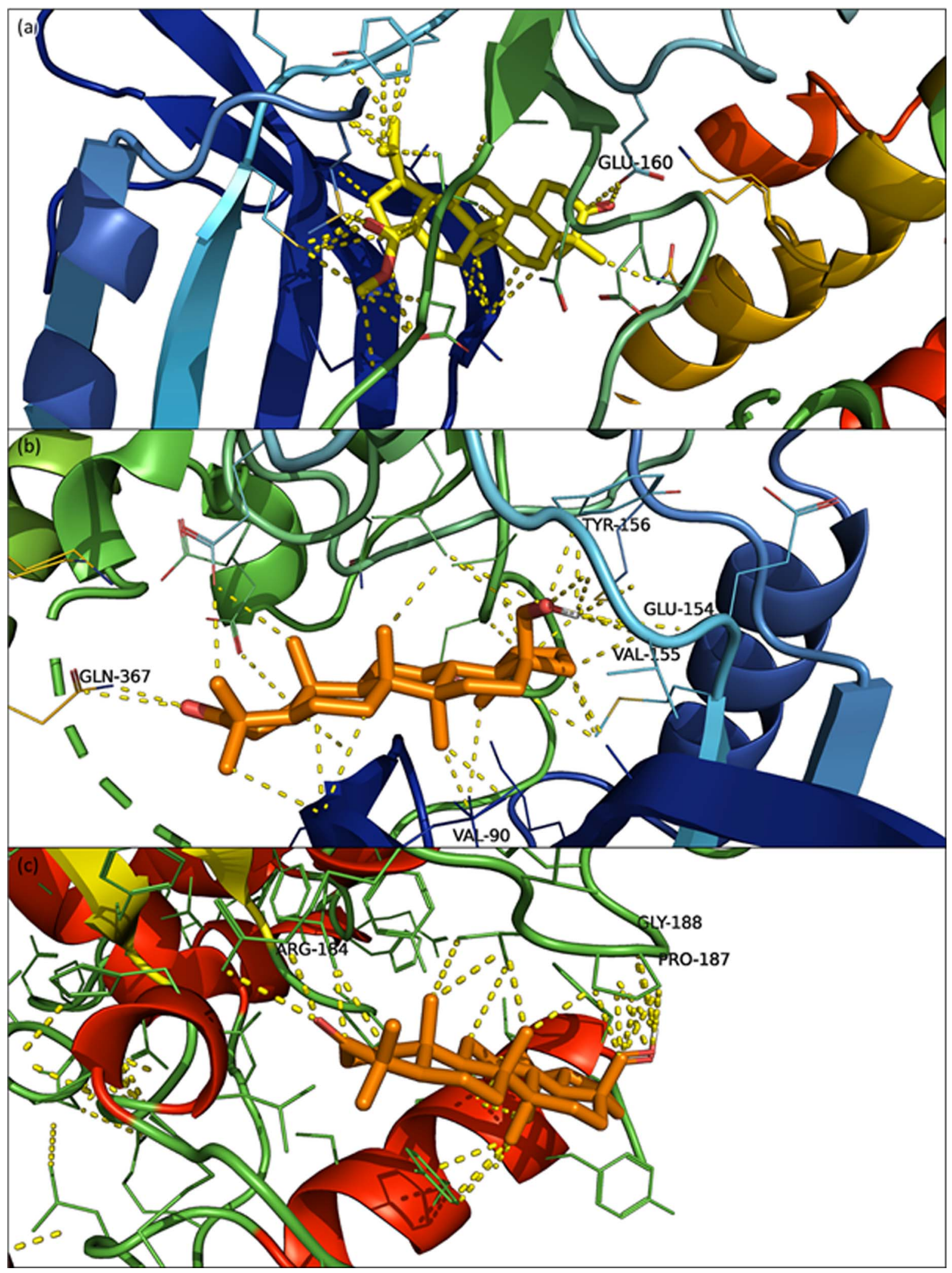

Figure 4. (a) PyMol visualization of the binding site of BAME (yellow) with PDB ID 3HZT (a); betulone (orange) in protein with PDB ID 3HZT (b); betulone (orange) with PDB ID 2050 (c). Yellow dotted lines represent contacts between the complexes within $3.5 \AA$. Labeled residues associated with yellow dotted lines are contacts within $3 \AA$. 
with PDB ID 3BYV since it does not have a co-crystallized ligand.

PyMol visualization of the BAME and PDB ID 3HZT protein complex shows that BAME was located in a pocket in which the co-crystallized ligand (PDB ID J60) is also located in the original $3 \mathrm{HZT}$ structure (Fig. $3 \mathrm{~d}$ ). Within $3 \AA$, the interaction analysis tool indicated polar contact between the ketone in position 3 and the residue GLU-160. Within $3.5 \AA$, the methyl ester in position 28 and the isopropyl group in position 19 of BAME seem to strongly interact with the residues of the cavity together with the $\mathrm{CH}_{2}$ and $\mathrm{CH}_{3}$ groups of the lupane backbone. This suggests strong interactions between BAME and the protein. These observations reinforce the conclusions drawn from the results shown in Table 4: there is a high affinity between BAME and the PDB ID 3HZT protein.

The complex betulone-3HZT showed the second-best free energy of binding equal to $-11.52 \mathrm{kcal} / \mathrm{mol}$ and corresponded to a cluster population of 149 . Visualization of the complex with PyMol showed that betulone was placed in the same cavity as BAME but was inverted lengthwise (Fig. 3a). Despite this, betulone still showed strong interactions with this receptor (Fig. 4b). Within $3 \AA$, polar contacts could be determined between the ketone in position C3 and GLN-367, and a polar area was defined between the $\mathrm{C} 18$ hydroxyl and residues GLU-154/VAL-155/TYR-156. Non-polar contact was established between the methyl group in position 27 with the residue VAL-90. Finally, many additional contacts were identified within $3.5 \AA$. Since the ligand can move within the cavity, these contacts provide a strong interaction between betulone and the protein.

Finally, the interaction between betulone and PDB ID 2050 was studied since it was the first result obtained with the reverse docking process (Table 3). Within $3 \AA$, PyMol visualization of the complex betulone-2O50 (Fig. 4c) highlighted electrostatic interactions between residue ARG-184 and ketone in C3 of betulone and between residues PRO-187/GLY-188 and $\mathrm{CH}_{2}-\mathrm{OH}$ in position 28 of betulone. Within $3.5 \AA$, the lupane backbone seems to interact with the protein and a pi-stacking is even supposed with a tyrosine. Together with the backbone, the ketone and the $\mathrm{CH}_{2}-\mathrm{OH}$ functions seem to stabilize betulone in the cavity.

\section{Discussion}

In a previous study [9], we demonstrated that the $n$-heptane extract of Alnus glutinosa bark had anti-Toxoplasma gondii activity. A bio-guided fractionation achieved by centrifugal partition chromatography and ${ }^{13} \mathrm{C}$ NMR-based dereplication showed that the active fractions were mainly composed of lupane-type triterpenes. As a result, six triterpenes were isolated from these triterpene-rich fractions (betulin, betulinaldehyde, betulinic acid, betulone, lupeol, and lupenone) but only the five first compounds were tested. $\beta$-sitostenone was also isolated since it was a major constituent of the active fractions, but it revealed no specific activity. Their antiparasitic evaluation against $T$. gondii indicates that betulone showed the highest activity with an $\mathrm{IC}_{50}$ of $2.7 \mu \mathrm{M}$, while lupeol (5) had the highest $\mathrm{IC}_{50}$ at $13.8 \mu \mathrm{M}$. The selectivity indexes were all greater than
5.8, but since the compounds were not soluble at a higher concentration of $80 \mu \mathrm{M}$ in the protocol, IS could not be precisely measured. Nevertheless, the $\mathrm{CC}_{50}$ from betulin on Vero cells was previously determined to be $164 \mu \mathrm{M}$ [17]. Thus, in our context, the SI of betulone could be greater than 29 . Only a few articles report the potential anti-T. gondii of triterpenes and most of them present lower activity than that obtained in this study. For example, maslinic acid - an oleanane-type triterpene - shows an $\mathrm{LD}_{50}$ of $53.8 \mu \mathrm{M}$ for $T$. gondii [10] and an $\mathrm{LD}_{50}$ of $236.6 \mu \mathrm{M}$ for Vero cells [10]. This suggests that lupane-type triterpenes have a higher anti- $T$. gondii potential than other triterpene types. This can be likened to conclusions reported by Gachet et al. highlighting that betulone (2) possesses interesting pharmacological activities especially on Plasmodium falciparum $\mathrm{K} 1$ strain, another apicomplexa, with an $\mathrm{IC}_{50}$ of $3.0 \mu \mathrm{M}$ and SI of 7.4 [16].

Betulin and especially its oxo-derivatives (betulone, betulinic and betulonic aldehydes, and betulinic and betulonic acids) have valuable biologically active properties that were previously reported. For instance, betulinic acid and its derivatives exhibit anti-cancer, anti-HIV, antiviral, anti-inflammatory, antiseptic, antimicrobial, anti-malarial, anti-leishmaniasis, anthelmintic, and fungicidal activities, while betulonic acid shows pronounced anti-inflammatory, antimelanoma, and antiviral effects. The 3-oxo derivatives of betulin - betulone and its derivatives exhibit antitumor, anti-inflammatory, antiparasitic, and anti-HIV properties [31]. Domínguez-Carmona et al. showed that C3 hydroxyl group oxidation of betulin to produce betulonic acid resulted in a significant increase of leishmanicidal activity against L. amazonensis [13]. In our study, we observed that the presence of ketone and hydroxyl functions in $\mathrm{C} 3$ and $\mathrm{C} 28$, respectively, corresponding to betulone, enhanced the anti- $T$. gondii activity. Two commercial compounds, betulonic acid and betulonic acid methyl ester were then tested to validate this hypothesis and they showed $\mathrm{IC}_{50}$ of $4.3 \mu \mathrm{M}$ and $3.1 \mu \mathrm{M}$, respectively without cytotoxicity at $80 \mu \mathrm{M}$ on Vero cells. This confirmed that ketone on $\mathrm{C} 3$ improves lupane type triterpene ability to inhibit $T$. gondii growth. Da Cunha et al. showed that at the concentration of $50 \mu \mathrm{M}$, the inhibition of $L$. donovani, which was $35.0 \%$ and $39.8 \%$ with betulin and betulinic acid, respectively reached $97.6 \%$ with betulonic acid [6]. Isah et al. also showed structural modification especially at $\mathrm{C} 3$ and $\mathrm{C} 27$ of the parent backbone of pentacyclic triterpenes improved antiparasitic activity in some cases and loss of activity in others [19]. All these results confirm that ketone in C3 and hydroxyl or aldehyde on C28 improves the ability of lupane type triterpenes to inhibit parasite growth.

To investigate the mechanism of action of betulone on T. gondii, an inverse docking study of betulone on 87 proteins was carried out, highlighting a strong interaction between betulone and three $T$. gondii proteins identified as CDPK3 (PDB ID 3HZT), ENR (PDB ID 2O50), and a rhoptry domain kinase ROP8 (PDB ID 3BYV). These proteins are not found in the human body, which is interesting in terms of selectivity towards parasitic rather than human biological targets. CDPK3 is a calcium-dependent protein kinase involved in the specific calcium-signaling pathway in plants and apicomplexans. The inhibition of this protein could lead to the alteration of motility, 
cell invasion, and egress disruption [45]. There are only few publications describing the activity of pentacyclic triterpenes on CDPK. Nevertheless, one of them mentions that ursolic acid derivatives are active against $T$. gondii in vivo by inhibiting the proliferation of the parasite in the mouse abdominal cavity and in the same publication, Luan et al. identified CDPK1 (PDB ID 6BFA) as a potential target [23]. This protein is also involved in T. gondii egress regulation as well as CDPK3 [22]. These two results support the hypothesis that CDPK3 is a potential target of lupane type triterpenes.

Enoyl-acyl carrier protein reductases (ENR) are strongly involved in type II fatty acid synthesis and are considered essential for bacterial and protozoal survival. This is a target found in narrow-spectrum antibacterial drugs [28]. The prokaryotic-like type II fatty acid biosynthetic pathway in T. gondii is a validated molecular target in tachyzoites, it is essential for parasite survival in vitro and in vivo [27]. In particular, the enoyl reductase (ENR) enzyme, which catalyzes the last reductive step of the type II fatty acid synthesis pathway, is present in all $T$. gondii life cycle stages except microgametes and ENRs in other organisms may be the target for a wide range of potent inhibitors. Importantly, compounds that inhibit type II fatty acid synthesis (including triclosan and several newly designed and synthesized compounds) not only inhibit $T$. gondii tachyzoite growth, but are also effective against other apicomplexan parasites, such as Plasmodium. ENR is inhibited by the antibacterial compound triclosan which inhibits in vitro growth of $T$. gondii with $\mathrm{IC}_{50}$ of $3.0 \mu \mathrm{M}$ [41]. Triclosan was found to inhibit $P$. falciparum growth with an $\mathrm{IC}_{50}$ of $1 \mu \mathrm{M}$ [28]. The co-location of betulone and triclosan in the ENR binding site is consistent with the likely high affinity between betulone and ENR.

PDB ID 3BYV refers to rhoptry antigen kinase domain ROP8. The rhoptries can be released in the host cell in the internalization process. Even if the mechanism is not well known, these proteins could participate in a momentary breach in the cytoplasmic membrane of the host cell. According to Qiu et al., this X-ray crystal structure was catalytically inactive but remains a template for the study of the major kinase ROP8 [33]. The interaction between pentacyclic triterpenes and ROP8 had never been reported before.

For the three proteins, there are many arguments that prove that the $\mathrm{C} 3$ oxidation level of betulone plays a major role in protein-ligand interactions, which can explain the in vitro results obtained in the framework of this work. Hydroxyl in C28 of betulone also interacts with amino acids of CDPK3 and ENR, but to date there is no evidence to support an interaction with ROP8.

In conclusion, this article highlighted the anti- $T$. gondii activity of lupane-type triterpenes isolated from black alder bark and the strong activity of betulone. Chemosensitivity of T. gondii to isolated triterpenes highlighted the importance of the ketone at the $\mathrm{C} 3$ position and the hydroxyl in C28. Reverse docking suggests that CDPK3, ENR, and ROP8 are potential targets for betulone, and interaction analysis confirmed the role of the functions in C3 and C28 deduced from preliminary structure-activity relationship studies. Further docking studies could be carried out on the three proteins with lupane-type triterpene derivatives that present a ketone in $\mathrm{C} 3$ and various functions in C28 to further the study of the anti-toxoplasmosis potential of lupane-type triterpenes. In addition, since these compounds cannot be correctly absorbed by the gastrointestinal tract or cross the blood-brain barrier, the candidates should be pharmacomodulated to improve these parameters before in vivo studies. In parallel, complementary studies should be carried out to develop galenic formulations including for instance microencapsulated triterpenes to overcome the solubility issues.

\section{Conflict of interest}

The authors declare that they have no conflict of interest associated with this publication.

Acknowledgements. The forestry harvesting company Hubert Cie (Illy, France) and the "Office National des Forêts" section of Signy L'Abbaye (Signy L'Abbaye, France) are acknowledged for tree bark collection. The authors thank the HPC-Regional Center ROMEO (https://romeo.univ-reims.fr/) and the Chaire MAgICS (Université de Reims Champagne-Ardenne) for their support and the Centre Hospitalier Universitaire de Reims and Grand Est region (France). This research was partially funded by the Interreg North-West Europe program: AgriWasteValue, grant number NWE 750.

\section{References}

1. Abedini A, Chollet S, Angelis A, Borie N, Nuzillard J-M, Skaltsounis A-L, Reynaud R, Gangloff SC, Renault J-H, Hubert J. 2016. Bioactivity-guided identification of antimicrobial metabolites in Alnus glutinosa bark and optimization of oregonin purification by centrifugal partition chromatography. Journal of Chromatography B, 1029-1030, 121-127.

2. Barthel A, Stark S, Csuk R. 2008. Oxidative transformations of betulinol. Tetrahedron, 64, 9225-9229.

3. del Carmen Recio M, Giner R, Máñez S, Ríos J. 1995. Structural requirements for the anti-inflammatory activity of natural triterpenoids. Planta Medica, 61, 182-185.

4. Carpenter RC, Sotheeswaran S, Sultanbawa MUS, Ternai B. 1980. ${ }^{13} \mathrm{C}$ NMR studies of some lupane and taraxerane triterpenes. Organic Magnetic Resonance, 14, 462-465.

5. Cháirez-Ramírez M, Moreno-Jiménez M, González-Laredo R, Gallegos-Infante J, Rocha-Guzmán N. 2016. Lupane-type triterpenes and their anti-cancer activities against most common malignant tumors: a review. EXCLI Journal, 15, Doc758. ISSN 1611-2156.

6. da Cunha EFF, Ramalho TC, Mancini DT, Fonseca EMB, Oliveira AA. 2010. New approaches to the development of antiprotozoan drug candidates: a review of patents. Journal of the Brazilian Chemical Society, 21, 1787-1806.

7. Daina A, Zoete V. 2016. A BOILED-Egg to predict gastrointestinal absorption and brain penetration of small molecules. ChemMedChem, 11, 1117-1121.

8. Darme P, Dauchez M, Renard A, Voutquenne-Nazabadioko L, Aubert D, Escotte-Binet S, Renault J-H, Villena I, Steffenel LA, Baud S. 2021. AMIDE v2: high-throughput screening based on AutoDock-GPU and improved workflow leading to better performance and reliability. International Journal of Molecular Sciences, 22, 7489. 
9. Darme P, Spalenka J, Hubert J, Escotte-binet S, Debelle L, Villena I, Sayagh C, Borie N, Martinez A, Bertaux B, Voutquenne-nazabadioko L, Renault J-H, Aubert D. 2021. Investigation of antiparasitic activity of ten European tree bark extracts on Toxoplasma gondii and bioguided identification of triterpenes in Alnus glutinosa barks. Antimicrobial Agents and Chemotherapy, 66, e01098-21. https://doi.org/10.1128/ AAC.01098-21.

10. De Pablos LM, González G, Rodrigues R, García Granados A, Parra A, Osuna A. 2010. Action of a pentacyclic triterpenoid, maslinic acid, against Toxoplasma gondii. Journal of Natural Products, 73, 831-834.

11. Dias R, Azevedo W de Jr. 2008. Molecular docking algorithms. Current Drug Targets, 9, 1040-1047.

12. Doliwa C, Escotte-Binet S, Aubert D, Velard F, Schmid A, Geers R, Villena I. 2013. Induction of sulfadiazine resistance in vitro in Toxoplasma gondii. Experimental Parasitology, 133, 131-136.

13. Domínguez-Carmona DB, Escalante-Erosa F, García-Sosa K, Ruiz-Pinell G, Gutierrez-Yapu D, Chan-Bacab MJ, GiménezTurba A, Peña-Rodríguez LM. 2010. Antiprotozoal activity of betulinic acid derivatives. Phytomedicine, 17, 379-382.

14. Endo M, Shigetomi K, Mitsuhashi S, Igarashi M, Ubukata M. 2019. Isolation, structure determination and structure-activity relationship of anti-toxoplasma triterpenoids from Quercus crispula Blume outer bark. Journal of Wood Science, 65, 1-11.

15. Felföldi-Gáva A, Szarka S, Simándi B, Blazics B, Simon B, Kéry Á. 2012. Supercritical fluid extraction of Alnus glutinosa (L.) Gaertn. Journal of Supercritical Fluids, 61, 55-61.

16. Gachet MS, Kunert O, Kaiser M, Brun R, Zehl M, Keller W, Muñoz RA, Bauer R, Schuehly W. 2011. Antiparasitic compounds from Cupania cinerea with activities against Plasmodium falciparum and Trypanosoma brucei rhodesiense. Journal of Natural Products, 74, 559-566.

17. Gong Y, Raj KM, Luscombe CA, Gadawski I, Tam T, Chu J, Gibson D, Carlson R, Sacks SL. 2004. The synergistic effects of betulin with acyclovir against herpes simplex viruses. Antiviral Research, 64, 127-130.

18. Hubert J, Angelis A, Aligiannis N, Rosalia M, Abedini A, Bakiri A, Reynaud R, Nuzillard J-M, Gangloff S, Skaltsounis A-L, Renault J-H. 2016. In vitro dermo-cosmetic evaluation of bark extracts from common temperate trees. Planta Medica, 82, $1351-1358$

19. Isah MB, Ibrahim MA, Mohammed A, Aliyu AB, Masola B, Coetzer THT. 2016. A systematic review of pentacyclic triterpenes and their derivatives as chemotherapeutic agents against tropical parasitic diseases. Parasitology, 143, 1219-1231.

20. Lipinski CA, Lombardo F, Dominy BW, Feeney PJ. 1997. Experimental and computational approaches to estimate solubility and permeability in drug discovery and development settings. Advanced Drug Delivery Reviews, 23, 3-25.

21. Loggia R, Tubaro A, Sosa S, Becker H, St Saar, Isaac O. 1994. The role of triterpenoids in the topical anti-inflammatory activity of Calendula officinalis flowers. Planta Medica, 60, 516-520.

22. Long S, Wang Q, Sibley LD. 2016. Analysis of noncanonical calcium-dependent protein kinases in Toxoplasma gondii by targeted gene deletion using CRISPR/Cas9. Infection and Immunity, 84, 1262-1273.

23. Luan T, Jin C, Jin C-M, Gong G-H, Quan Z-S. 2019. Synthesis and biological evaluation of ursolic acid derivatives bearing triazole moieties as potential anti-Toxoplasma gondii agents. Journal of Enzyme Inhibition and Medicinal Chemistry, 34, 761-772.

24. Luft BJ, Remington JS. 1992. Toxoplasmic encephalitis in AIDS. Clinical Infectious Diseases, 15, 211-222.
25. Mahato SB, Kundu AP. 1994. ${ }^{13}$ C NMR Spectra of pentacyclic triterpenoids - a compilation and some salient features. Phytochemistry, 37, 1517-1575.

26. Mao D-B, Feng Y-Q, Bai Y-H, Xu C-P. 2012. Novel biotransformation of betulin to produce betulone by Rhodotorula mucilaginosa. Journal of the Taiwan Institute of Chemical Engineers, 43, 825-829.

27. Mazumdar J, Wilson EH, Masek K, Hunter CA, Striepen B. 2006. Apicoplast fatty acid synthesis is essential for organelle biogenesis and parasite survival in Toxoplasma gondii. Proceedings of the National Academy of Sciences, 103, 1319213197.

28. McLeod R, Muench SP, Rafferty JB, Kyle DE, Mui EJ, Kirisits MJ, Mack DG, Roberts CW, Samuel BU, Lyons RE, Dorris M, Milhous WK, Rice DW. 2001. Triclosan inhibits the growth of Plasmodium falciparum and Toxoplasma gondii by inhibition of apicomplexan Fab I. International Journal for Parasitology, 31, 109-113.

29. Montazeri M, Mehrzadi S, Sharif M, Sarvi S, Tanzifi A, Aghayan SA, Daryani A. 2018. Drug resistance in Toxoplasma gondii. Frontiers in Microbiology, 9, 2587.

30. Montoya J, Liesenfeld O. 2004. Toxoplasmosis. The Lancet, 363, 1965-1976.

31. Kolobova EN, Pakrieva EG, Carabineiro SAC, Bogdanchikova N, Kharlanov AN, Kazantsev SO, Hemming J, Mäki-Arvela P, Pestryakov AN, Murzin DY. 2019. Oxidation of a wood extractive betulin to biologically active oxo-derivatives using supported gold catalysts. Green Chemistry, 21, 3370-3382.

32. Prachayasittikul S, Suphapong S, Worachartcheewan A, Lawung R, Ruchirawat S, Prachayasittikul V. 2009. Bioactive metabolites from Spilanthes acmella Murr. Molecules, 14, 850 867.

33. Qiu W, Wernimont A, Tang K, Taylor S, Lunin V, Schapira M, Fentress S, Hui R, Sibley LD. 2009. Novel structural and regulatory features of rhoptry secretory kinases in Toxoplasma gondii. EMBO Journal, 28, 969-979.

34. Räsänen R-M, Hieta J-P, Immanen J, Nieminen K, Haavikko R, Yli-Kauhaluoma J, Kauppila TJ. 2019. Chemical profiles of birch and alder bark by ambient mass spectrometry. Analytical and Bioanalytical Chemistry, 411, 7573-7583.

35. Reynolds MG, Oh J, Roos DS. 2001. In vitro generation of novel pyrimethamine resistance mutations in the Toxoplasma gondii dihydrofolate reductase. Antimicrobial Agents and Chemotherapy, 45, 1271-1277.

36. de Sá MS, Costa JFO, Krettli AU, Zalis MG, de Azevedo Maia GL, Sette IMF, de Amorim Câmara C, Filho JMB, GiuliettiHarley AM, Ribeiro dos Santos R, Soares MBP. 2009. Antimalarial activity of betulinic acid and derivatives in vitro against Plasmodium falciparum and in vivo in $P$. bergheiinfected mice. Parasitology Research, 105, 275-279.

37. Salomane N, Pooe OJ, Simelane MBC. 2021. Iso-mukaadial acetate and ursolic acid acetate inhibit the chaperone activity of Plasmodium falciparum heat shock protein 70-1. Cell Stress and Chaperones, 26, 685-693.

38. Seeliger D, de Groot BL. 2010. Ligand docking and binding site analysis with PyMOL and Autodock/Vina. Journal of Computer-Aided Molecular Design, 24, 417-422.

39. Sholichin M, Yamasaki K, Kasai R, Tanaka O. $1980 .{ }^{13} \mathrm{C}$ nuclear magnetic resonance of lupane-type triterpenes, lupeol, betulin and betulinic acid. Chemical and Pharmaceutical Bulletin, 28, 1006-1008.

40. Spalenka J, Escotte-Binet S, Bakiri A, Hubert J, Renault J-H, Velard F, Duchateau S, Aubert D, Huguenin A, Villena I. 2018. Discovery of new inhibitors of Toxoplasma gondii via the pathogen box. Antimicrobial Agents and Chemotherapy, 62, e01640-17. 
41. Stec J, Fomovska A, Afanador GA, Muench SP, Zhou Y, Lai BS, El Bissati K, Hickman MR, Lee PJ, Leed SE, Auschwitz JM, Sommervile C, Woods S, Roberts CW, Rice D, Prigge ST, McLeod R, Kozikowski AP. 2013. Modification of triclosan scaffold in search of improved inhibitors for enoyl-acyl carrier protein (ACP) reductase in Toxoplasma gondii. ChemMedChem, 8, 1138-1160.

42. Sun H, Fang W-S, Wang W-Z, Hu C. 2006. Structure-activity relationships of oleanane- and ursane- type triterpenoids. Botanical Studies, 47, 31.

43. Vasseur R, Baud S, Steffenel LA, Vigouroux X, Martiny L, Krajecki M, Dauchez M, Team S, Ea Cr. 2014. AMIDE Automatic Molecular Inverse Docking Engine for large-scale protein targets identification. International Journal on Advances in Life Sciences, 6, 325-337.

44. Vasseur R, Baud S, Steffenel LA, Vigouroux X, Martiny L, Krajecki M, Dauchez M. 2015. Inverse docking method for new proteins targets identification: A parallel approach. Parallel Computing, 42, 48-59.
44. Vasseur R, Baud S, Steffenel LA, Vigouroux X, Martiny L, Krajecki M, Dauchez M. 2015. Inverse docking method for new proteins targets identification: a parallel approach. Parallel Computing, 42, 48-59.

45. Wernimont AK, Artz JD, Finerty P, Lin Y-H, Amani M, AllaliHassani A, Senisterra G, Vedadi M, Tempel W, Mackenzie F, Chau I, Lourido S, Sibley LD, Hui R. 2010. Structures of apicomplexan calcium-dependent protein kinases reveal mechanism of activation by calcium. Nature Structural \& Molecular Biology, 17, 596-601.

46. Zhang L-H, Jin L-L, Liu F, Jin C, Jin C-M, Wei Z-Y. 2020. Evaluation of ursolic acid derivatives with potential antiToxoplasma gondii activity. Experimental Parasitology, 216, 107935.

47. Ziegler HL, Franzyk H, Sairafianpour M, Tabatabai M, Tehrani MD, Bagherzadeh K, Hägerstrand H, Stærk D, Jaroszewski JW. 2004. Erythrocyte membrane modifying agents and the inhibition of Plasmodium falciparum growth. Bioorganic \& Medicinal Chemistry, 12, 119-127.

Cite this article as: Darme P, Escotte-Binet S, Cordonnier J, Remy S, Hubert J, Sayagh C, Borie N, Villena I, Voutquenne-Nazabadioko L, Dauchez M, Baud S, Renault J \& Aubert D. 2022. Anti-Toxoplasma gondii effect of lupane-type triterpenes from the bark of black alder (Alnus glutinosa) and identification of a potential target by reverse docking. Parasite 29, 7.

\section{PARASTE}

An international open-access, peer-reviewed, online journal publishing high quality papers on all aspects of human and animal parasitology

Reviews, articles and short notes may be submitted. Fields include, but are not limited to: general, medical and veterinary parasitology; morphology, including ultrastructure; parasite systematics, including entomology, acarology, helminthology and protistology, and molecular analyses; molecular biology and biochemistry; immunology of parasitic diseases; host-parasite relationships; ecology and life history of parasites; epidemiology; therapeutics; new diagnostic tools.

All papers in Parasite are published in English. Manuscripts should have a broad interest and must not have been published or submitted elsewhere. No limit is imposed on the length of manuscripts.

Parasite (open-access) continues Parasite (print and online editions, 1994-2012) and Annales de Parasitologie Humaine et Comparée (1923-1993) and is the official journal of the Société Française de Parasitologie. 